\title{
Perancangan Sistem Pendukung Keputusan Sertifikasi Pendidik Guru SMP Di Kabupaten Murung Raya Dengan Metode Simple Additive Weighting (SAW)
}

Jadiaman Parhusip ${ }^{\text {a.1.* }}$

Teknik Informatika Universitas Palangka Raya, Jl. W. Condrad, Palangka Raya

parhusip.jadiaman@it.upr.ac.id

\section{ARTICLE INFO}

Keywords

Teacher Certification

Decision Support System

Simple Additive Weighting

Murung Raya

Borland Delphi

\begin{abstract}
Means of government to improve quality of teacher is accomplished through teacher certification. It is done by selecting every teacher listed in Education Board in Indonesia. Lots of data of participants of the teacher certification and confusion of criteria in selection of the teacher certification done by committee of the teacher certification can cause inaccurate data of the eligible participants to be certified. It causes gap for teacher which is actually eligible to be certified. To overcome the situation, it is necessary to produce a computer-based systematic effort for every working unit, in this case is Education Board of Murung Raya Regency in Central Kalimantan. The Development of Decision Support System which was used in this study was started by analyzing available system and analyzing related literature, Government Regulations, which was used as legal foundation to process data related to the teacher certification. Teacher certification scoring used Simple Additive Weighting (SAW), which scored every datum and then was normalized by matrix. The result of matrix normalization obtained the final score of 7 (seven) criteria for every teacher which later will be ranked from the highest to the lowest. The rank was utilized to decide priority of teacher which was eligible to be certified. This application used Borland Delphi 7 as the programming language and MySQL as the database engine. The result of this study was a helping application to recommend teacher certification. Data which was produced by the application showed the similar result compared with the result of manual scoring from the institution.
\end{abstract}

\section{Pendahuluan}

Tuntutan terhadap guru yang berkompetensi telah menjadi keniscayaan agar dengan kompetensinya tersebut lebih mampu dalam menjalankan tugas dan tanggungjawabnya. Tidak setiap guru secara otomatis boleh mendapatkan pengakuan profesionalitasnya, melainkan harus memiliki beberapa kriteria sebagaimana telah ditetapkan oleh negara. Supaya fungsi dan tugas yang melekat pada jabatan fungsional guru dilaksanakan sesuai dengan aturan yang berlaku, maka diperlukan penilaian kelayakan guru untuk mendapatkan sertifikasi sebagai pendidik yang diharapkan lebih menjamin terjadinya proses Kegiatan Belajar Mengajar (KBM) yang berkualitas bagi anak didik yang menjadi tanggungjawabnya. Dinas Pendidikan Kabupaten Murung Raya mengelola banyak sekali data guru yang akan diproses guna mendapatkan sertifikasi pendidik pada berbagai tingkatan pendidikan, untuk itu diperlukan sistem berbasis komputer, dan metode yang dipilih adalah Simple Additive 
Weighting (SAW), serta yang menjadi sasaran pertama uji coba adalah guru di tingkat Sekolah Menengah Pertama (SMP).

\subsection{Teori Sertifikasi}

Menurut Kamus Besar Bahasa Indonesia (KBBI), sertifikasi berasal dari kata sertifikat; Sertifikasi merupakan proses penyertifikatan, adalah suatu penetapan yang diberikan oleh suatu organisasi profesional terhadap seseorang untuk menunjukkan bahwa orang tersebut mampu untuk melakukan suatu pekerjaan atau tugas spesifik. Sertifikasi biasanya harus diperbaharui secara berkala, atau dapat pula hanya berlaku untuk suatu periode tertentu. Sebagai bagian dari pembaharuan sertifikasi, umumnya diterapkan bahwa seorang individu harus menunjukkan bukti pelaksanaan pendidikan berkelanjutan atau memperoleh nilai CEU (continuing education unit).

Secara umum pengertian sertifikasi guru adalah proses pemberian sertifikat pendidik kepada guru. Sertifikat pendidik diberikan kepada guru yang telah memenuhi standar profesi guru. Guru yang telah memiliki sertifikat berarti telah mempunyai kualifikasi mengajar seperti yang dijelaskan di dalam sertifikat itu.

Berikut ini dikutipkan dari beberapa pasal yang tertuang dalam Undang-Undang Republik Indonesia Nomor 14 Tahun 2005 tentang Guru dan Dosen sebagai berikut[1] :

a. Pasal 1 butir 11: Sertifikasi adalah proses pemberian sertifikat pendidik kepada guru dan dosen.

b. Pasal 8: Guru wajib memiliki kualifikasi akademik, kompetensi, sertifikasi pendididk, sehat jasmani dan rohani, serta memiliki kemampuan untuk mewujudkan tujuan pendidikan nasional.

c. Pasal 16: Guru yang memiliki sertifikat pendidik memperoleh tunjangan profesi sebesar satu kali gaji, guru negeri maupun swasta dibayar pemerintah. Dalam Undang-Undang Republik Indonesia Nomor 14 Tahun 2005 tentang guru dan dosen, dikemukakan bahwa sertifikasi adalah proses pemberian sertifikat pendidik untuk guru dan dosen.

Selanjutnya dengan sertifikasi diharapkan guru menjadi pendidik profesional, yaitu berkompetensi sebagai agen pembelajaran yang dibuktikan dengan memiliki sertifikat pendidikan setelah dinyatakan lulus uji kompetensi. Oleh karena itu, lewat sertifikasi ini diharapkan guru menjadi pendidik yang profesional, yaitu yang berpendidikan minimal S-1/D-4 dan berkompetensi. Atas profesinya itu, guru berhak mendapatkan imbalan (reward) berupa tunjangan profesi dari pemerintah sebesar satu kali gaji pokok [2].

Dari uraian sertifikasi diatas, maka dapat disimpulkan bahwa sertifikasi adalah dalam proses pemberian sertifikat pendidik kepada guru yang telah memenuhi persyaratan tertentu. Peningkatan mutu guru lewat program sertifikasi ini sebagai upaya peningkatan mutu pendidikan. Rasionalnya adalah apabila kompetensi guru bagus yang diikuti dengan penghasilan bagus, diharapkan kinerjanya juga bagus. Apabila kinerjanya bagus maka KBM-nya juga bagus. KBM yang bagus diharapkan dapat membuahkan pendidikan yang bermutu. Pemikiran itulah yang mendasari bahwa guru perlu disertifikasi.

\subsection{Perancangan Sistem}

Perancangan sistem adalah sekumpulan aktivitas yang menggambarkan secara rinci bagaimana sistem akan berjalan. Hal itu bertujuan untuk menghasilkan produk perangkat lunak yang sesuai dengan kebutuhan user [3]. Pendapat lain, oleh McLeod, Menurut McLeod perancangan sistem adalah penentuan proses dan data yang diperlukan oleh sistem baru, jika sistem itu berbasis komputer, perancangan dapat dinyatakan spesifikasi peralatan yang digunakan [4]. Pengertian sistem menurut Romney dan Steinbart, Sistem adalah rangkaian dari dua atau lebih komponen-komponen yang saling berhubungan, yang berinteraksi untuk mencapai suatu tujuan.Sebagian besar sistem terdiridari subsistem yang lebih kecil yang mendukung sistem yang lebih besar [5]. Dapat disimpulkan bahwa perencanaan sistem adalah proses penerjemahan kebutuhan pemakai informasi yang diperlukan oleh sistem yang ada serta untuk menunjang pengembangan sistem yang baru.

\subsection{Sistem Penunjang Keputusan}

Sistem Pendukung Keputusan (SPK) atau Decision Support System (DSS) adalah sebuah sistem yang mampu memberikan kemampuan pemecahan masalah maupun kemampuan pengkomunikasian 
untuk masalah dengan kondisi semi terstruktur dan tak terstruktur. Sistem ini digunakan untuk membantu pengambilan keputusan dalam situasi semi terstruktur dan situasi yang tidak terstruktur, dimana tak seorangpun tahu secara pasti bagaimana keputusan seharusnya dibuat [6]. SPK bertujuan untuk menyediakan informasi, membimbing, memberikan prediksi serta mengarahkan kepada pengguna informasi agar dapat melakukan pengambilan keputusan dengan lebih baik. SPK merupakan implementasi teori-teori pengambilan keputusan yang telah diperkenalkan oleh ilmu-ilmu seperti operation research dan menegement science, hanya bedanya adalah bahwa jika dahulu untuk mencari penyelesaian masalah yang dihadapi harus dilakukan perhitungan iterasi secara manual (biasanya untuk mencari nilai minimum, maksimum, atau optimum), saat ini computer PC telah menawarkan kemampuannya untuk menyelesaikan persoalan yang sama dalam waktu relatif singkat.

Sprague dan Watson mendefinisikan Sistem Pendukung Keputusan (SPK) sebagai sistem yang memiliki lima karakteristik utama yaitu; [7]

1. Sistem yang berbasis komputer

2. Dipergunakan untuk membantu para pengambil keputusan

3. Untuk memecahkan masalah-masalah rumit yang mustahil dilakukan dengan kalkulasi manual

4. Melalui cara simulasi yang interaktif

5. Dimana data dan model analisis sebagai komponen utama

\subsection{Simple Aditive Weighting}

Algoritma SAW (Simple Additive Weighting) adalah salah satu algoritma yang digunakan untuk pengambilan keputusan. Algoritma SAW juga dikenal dengan algoritma dengan metode penjumlahan berbobot. Metode ini membutuhkan proses normalisasi matrix keputusan (x) ke suatu skala yang dapat dibandingkan dengan semua rating alternatif yang ada [8].

Formula untuk melakukan normaliasai tersebut adalah sebagai berikut:

$$
r_{i j}= \begin{cases}\frac{x_{i j}}{\operatorname{Max}_{i} x_{i j}} & \text { jika } \mathrm{j} \text { adalah atribut keuntungan (benefit) } \\ \frac{\operatorname{Min}_{i} x_{i j}}{x_{i j}} & \text { jika j adalah atribut biaya (cost) }\end{cases}
$$

$\mathrm{r}_{\mathrm{ij}}=$ nilai rating kinerja ternormalisasi

$\mathrm{x}_{\mathrm{ij}}=$ nilai atribut yang dimiliki dari setiap kriteria

$\operatorname{Max}_{\mathrm{ij}}=$ nilai terbesar dari setiap kriteria $_{\mathrm{i}}$

Min $\mathrm{x}_{\mathrm{ij}}=$ nilai terkecil dari setiap kriteria ${ }_{\mathrm{i}}$

benefit $=$ jika nilai terbesar adalah terbaik

cost $=$ jika nilai terkecil adalah terbaik dimana $r_{i j}$ adalah rating kinerja ternormalisasi dari alternatif $A_{i}$ pada atribut $\mathrm{C}_{\mathrm{j}} ; \mathrm{i}=1,2, \ldots, \mathrm{m}$ dan $\mathrm{j}=1,2, \ldots, \mathrm{n}$.

Nilai preferensi untuk setiap alternatif (Vi) diberikan sebagai 


$$
V i=\sum_{j=1}^{n} w_{j} r_{i j}
$$

Keterangan :

$\mathrm{V}_{\mathrm{i}}=$ rangking untuk setiap alternatif

$\mathrm{w}_{\mathrm{j}}=$ nilai bobot dari setiap kriteria

$\mathrm{r}_{\mathrm{ij}}=$ nilai rating kinerja ternormalisasi

Nilai $V_{i}$ yang lebih besar mengindikasikan bahwa alternatif $A_{i}$ lebih terpilih.

1.5 Kelebihan dari Metode SAW[9]

a) Menentukan nilai bobot untuk setiap atribut kemudian dilanjutkan dengan proses perankingan yang akan menyeleksi alternatif terbaik dari sejumlah alternatif.

b) Penilaian akan lebih tepat karena didasarkan pada nilai kriteria dari bobot preferensi yang sudah ditentukan.

c) Adanya perhitungan normalisasi matriks sesuai dengan nilai atribut (antara nilai benefit dan cost).

\section{Metode Penelitian}

Berdasarkan dari informasi yang dikelola, maka jenis penelitian ini adalah penelitian deskriptif dengan pendekatan kuantitatif. Menurut Sugiyono, penelitian deskriptif yaitu penelitian yang dilakukan untuk mengetahui nilai variabel mandiri, baik satu variabel atau lebih (independen) tanpa membuat perbandingan, atau menghubungkan dengan variabel lain [10]. Penelitian ini dilakukan untuk memperoleh variabel-variabel dalam penelitian, penulis menentukan variabel-variabel yang diperoleh dari literatur kemudian dibuat kuesionernya dan disebarkan kepada pakar dan ahli.

\subsection{Pengumpulan Data}

Untuk mengumpulkan data dan informasi tersebut, penulis melakukan dengan 2 metode pengumpulan data yaitu pengumpulan data primer dan pengumpulan data sekunder.

\subsection{Instrumen Penelitian}

Penelitian ini menggunakan angket atau kuesioner yang digunakan sebagai instrumentasi guna memperoleh data dalam proses penentuan guru yang layak mendapatkan sertifikasi. Pada tahap awal pengumpulan data dilakukan penyebaran kuesioner kepada responden ahli (yang berwenang dalam hal sertifikasi guru) untuk mendapatkan calon kriteria-kriteria penentuan calon guru bersertifikat pada kantor Dinas Pendidikan Kabupaten Murung Raya.

\subsection{Teknik Analisa Data}

Dibuat program komputer menggunakan bahasa pemrograman Delphi.

\section{Hasil Dan Pembahasan}

Kriteria penentuan guru yang layak dapat sertifikasi menggunakan Peraturan Pemerintah Nomor 19 Tahun 2017 tentang Perubahan Atas Peraturan Pemerintah Nomor 74 Tahun 2008 Tentang Guru, yaitu di dalam Pasal 15 Nomor 4.

\subsection{Kriteria Penentuan Sertifikasi Guru SMP}

Kriteria berikut terdapat dalam Peraturan Pemerintah Nomor 19 Tahun 2017 tentang Perubahan Atas Peraturan Pemerintah Nomor 74 Tahun 2008 Tentang Guru, yaitu di dalam Pasal 15 Nomor 4. 


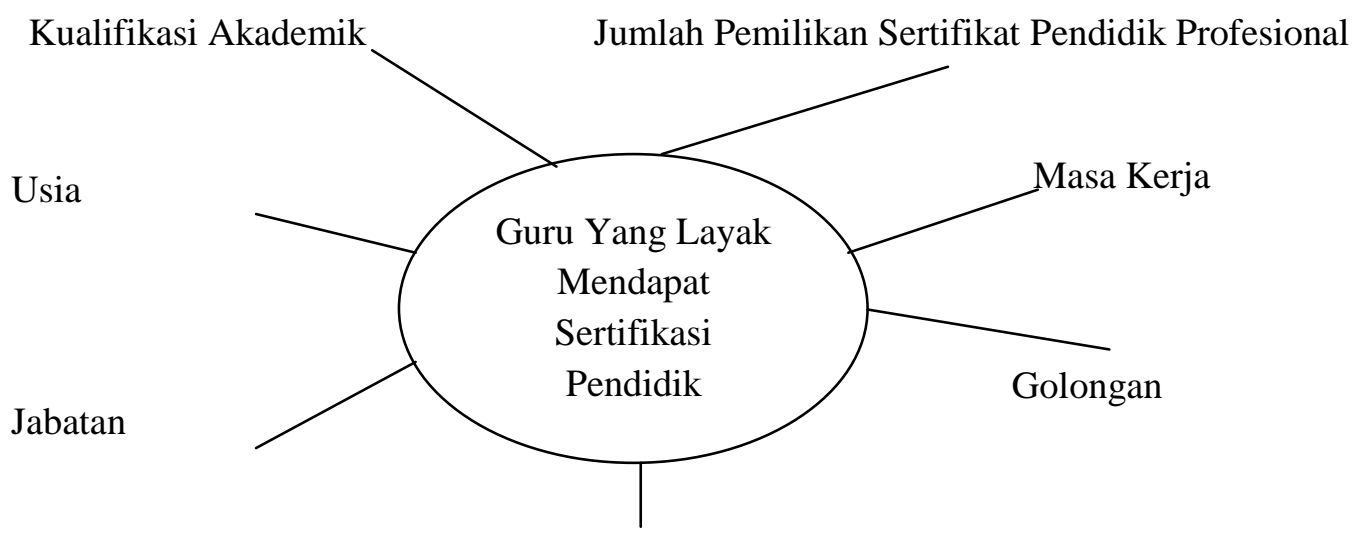

Waktu yang digunakan untuk tatap muka (mengajar) dalam seminggu

Gambar 1. Kriteria Guru Yang Layak Mendapatkan Sertifikasi Pendidik

Penjelasan mengenai penghitungan kriteria diatas:

i. Kualifikasi Akademik

Tabel 1. Kriteria Kualifikasi Akademik

\begin{tabular}{ccc}
\hline Kualifikasi Akademik (C1) & Keterangan & Nilai \\
\hline D4 / S1 & Sedang & 0,6 \\
\hline S2 & Tinggi & 0,8 \\
\hline S3 & Sangat Tinggi & 1 \\
\hline
\end{tabular}

ii. Usia

\begin{tabular}{ccc}
\hline Usia $(\mathbf{C 1})$ & Keterangan & Nilai \\
\hline $23-30$ & Rendah & 0,4 \\
\hline $31-40$ & Sedang & 0,6 \\
\hline $41-50$ & Tinggi & 0,8 \\
\hline $51-60$ & Sangat Tinggi & 1 \\
\hline
\end{tabular}

iii. Sertifikat Pendidik Profesional

Sertifikat Pendidik diperoleh apabila seorang guru telah menyelesaikan pelatihan PPG ataupun PLPG yang diprogramkan oleh Lembaga Pendidikan dan Tenaga Kependidikan (LPTK) sebagai salah satu syarat untuk mengajukan sertifikasi.

Tabel 3. Kriteria Sertifikat Pendidik Profesional

\begin{tabular}{ccc}
\hline Jumlah Pemilikan Sertifikat Pendidik (C3) & Keterangan & Nilai \\
\hline 1 Sertifikat & Baik & 0,5 \\
\hline$>$ 1 Sertifikat & Sangat Baik & 1 \\
\hline
\end{tabular}

*Ketentuan banyaknya jumlah sertifikat pendidik yang dapat diperoleh seorang guru diatur melalui Peraturan Pemerintah Nomor 19 Tahun 2017 tentang Perubahan Atas Peraturan Pemerintah Nomor 74 Tahun 2008 Tentang Guru Pasal 10 Ayat 5, yang mencantumkan: "Calon guru dapat memperoleh lebih dari satu (>1) Sertifikat Pendidik, tetapi hanya diberi satu nomor registrasi guru". 


\section{JURNAL TEKNOLOGI INFORMASI}

iv. Waktu yang digunakan untuk tatap muka (mengajar) dalam seminggu.

Tabel 4. Kriteria Jumlah Jam Mengajar

\begin{tabular}{ccc}
\hline Jam Mengajar $(\mathbf{C 4})$ & Keterangan & Nilai \\
\hline $24-25$ Jam & Cukup & 0,4 \\
\hline $26-27$ & Baik & 0,6 \\
\hline $28-29$ & Sangat Baik & 0,8 \\
\hline$>30$ Jam & Istimewa & 1 \\
\hline
\end{tabular}

v. Masa Kerja

\begin{tabular}{ccc}
\hline Masa Kerja (C5) & Keterangan & Nilai \\
\hline$<5$ & Sangat Kurang & 0,2 \\
\hline $6-10$ & Kurang & 0,4 \\
\hline $11-15$ & Cukup & 0,6 \\
\hline $16-20$ & Baik & 0,8 \\
\hline$>21$ & Sangat Baik & 1 \\
\hline
\end{tabular}

vi. Golongan

\begin{tabular}{ccc}
\hline Golongan (C6) & Keterangan & Nilai \\
\hline III A & Cukup & 0,5 \\
\hline III B & Sangat Cukup & 0,6 \\
\hline III C & Tinggi & 0,7 \\
\hline III D & Sangat Tinggi & 0,8 \\
\hline IV A & Istimewa & 0,9 \\
\hline IV B & Sangat Istimewa & 1 \\
\hline
\end{tabular}

vii. Jabatan

Tabel 7. Kriteria Jabatan

\begin{tabular}{ccc}
\hline Jabatan $(\mathbf{C 7})$ & Keterangan & Nilai \\
\hline Guru & Sedang & 0,5 \\
\hline Wakil Kepala Sekolah & Tinggi & 0,8 \\
\hline Kepala Sekolah & Sangat Tinggi & 1 \\
\hline
\end{tabular}

3.2 Skor Penilaian Tingkat Kepentingan

Skor penilaian tingkat kepentingan digunakan pada kuestioner dari aplikasi yang dibuat menggunakan program komputer Delphi dalam membandingkan antar kriteria dan antar alternatif guru yang dinilai. 


\section{JURNAL TEKNOLOGI INFORMASI}

\section{Jurnal keilmutan dan Aplikasi Bidang Teknik Informatika}

[E-ISSN 2656-0321]

[Vol 14 No 1]

[ Januari 2020]

Tabel 8. Skor Penilaian Tingkat Kepentingan

\begin{tabular}{clc}
\hline Kriteria & \multicolumn{1}{c}{ Keterangan } & Bobot (\%) \\
\hline C1 & Kualifikasi Akademik & 10 \\
\hline C2 & Usia & 5 \\
\hline C3 & Sertifikat Pendidik Profesional & 25 \\
\hline C4 & $\begin{array}{l}\text { Waktu yang digunakan untuk tatap muka (mengajar) } \\
\text { dalam seminggu }\end{array}$ & 25 \\
\hline C5 & Masa Kerja & 15 \\
\hline C6 & Golongan & 5 \\
\hline C7 & Jabatan & 15 \\
\hline
\end{tabular}

3.3 Halaman Penilaian

Proses penilaian menggunakan komputer dengan bahasa pemrograman Delphi, dengan tampilan antarmuka sebagai berikut.

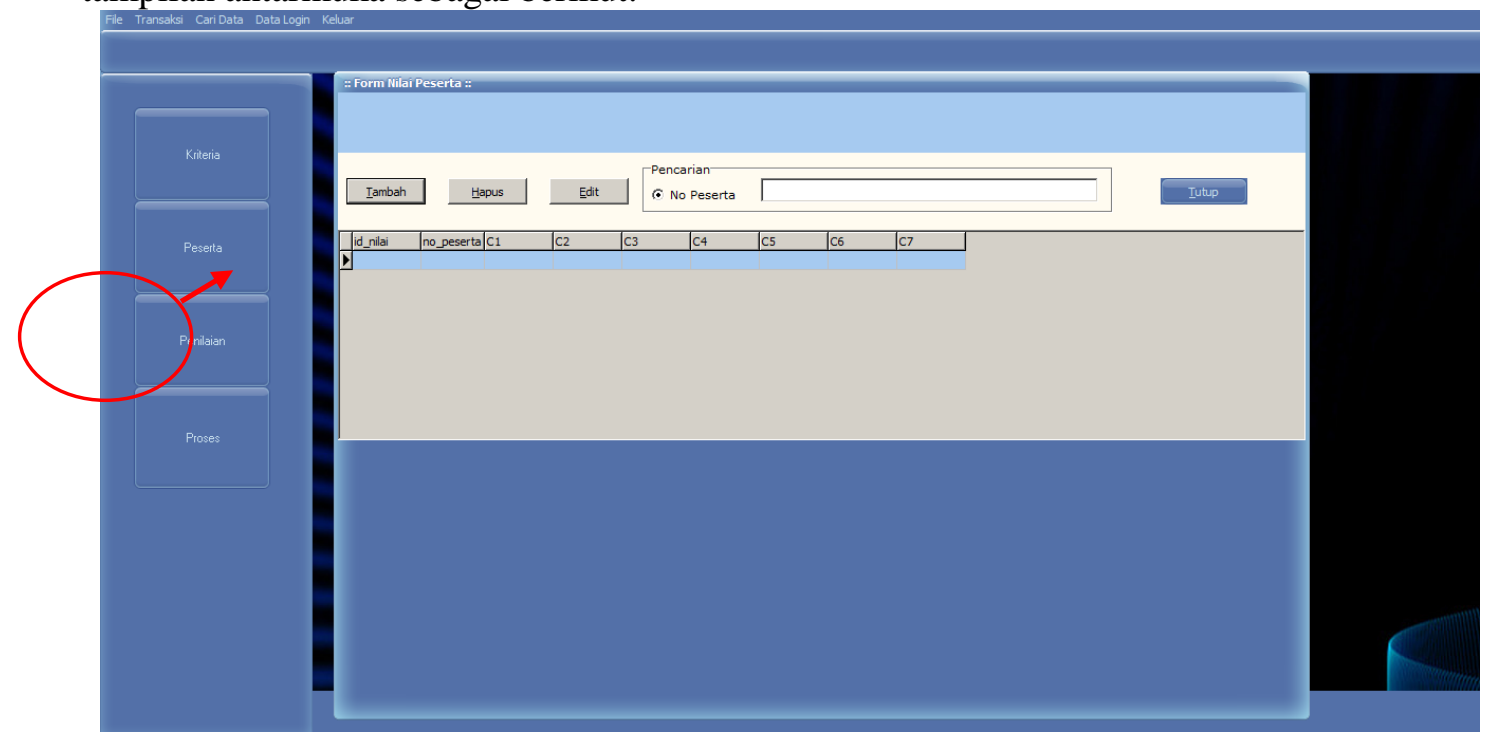

Gambar 2. Halaman Penilaian

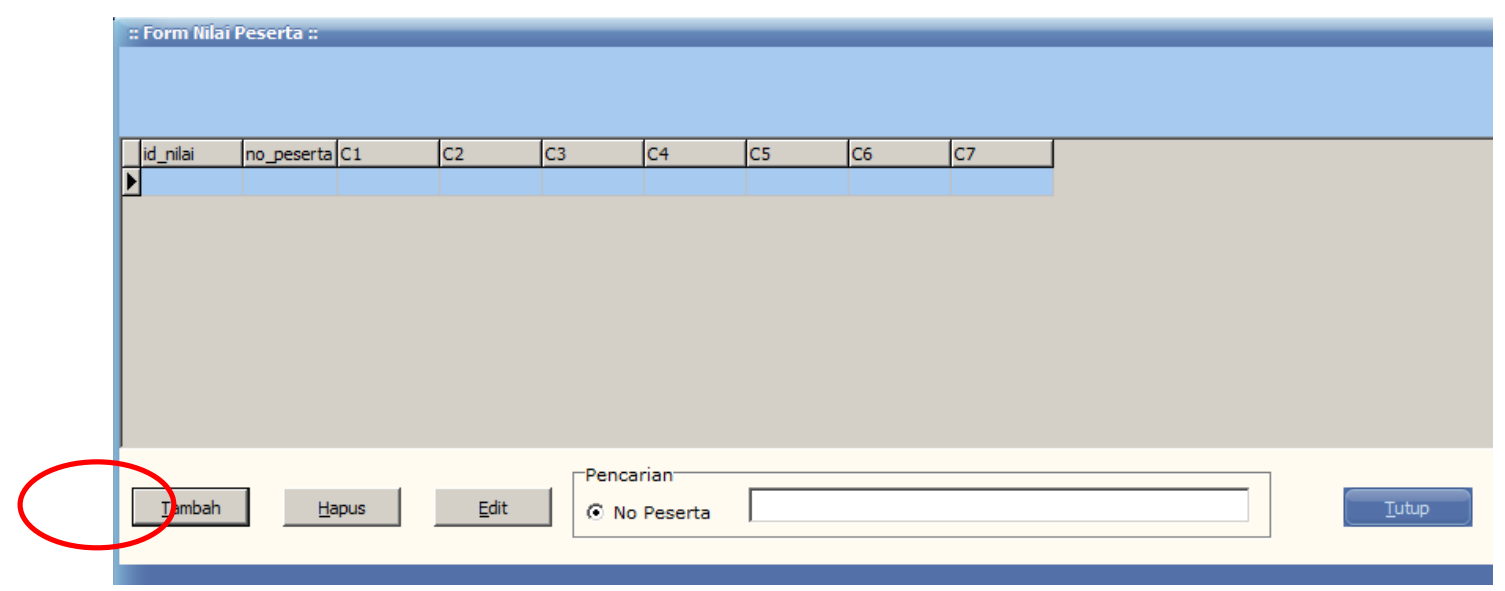

Gambar 3. Tambah Untuk Menginput Nilai Guru 


\section{JURNAL TEKNOLOGI INFORMASI}

Jurnal Keilmutan dan Aplikasi Biclang Teknik Informatika

[E-ISSN 2656-0321]

[Vol 14 No 1]

[ Januari 2020]

Alur pengerjaan pada halaman ini adalah sebagai berikut:

1) Pilih terlebih dahulu data salah satu guru yang telah diinputkan pada halaman peserta dengan mengklik titik tiga (...)

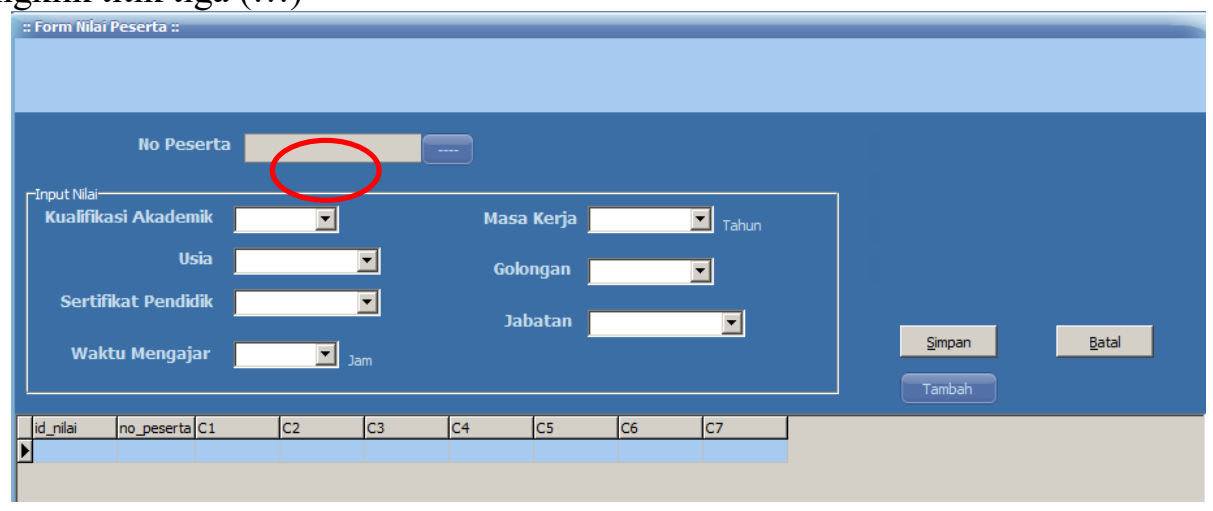

Gambar 4. Pilih Data Guru Yang Akan Dinilai

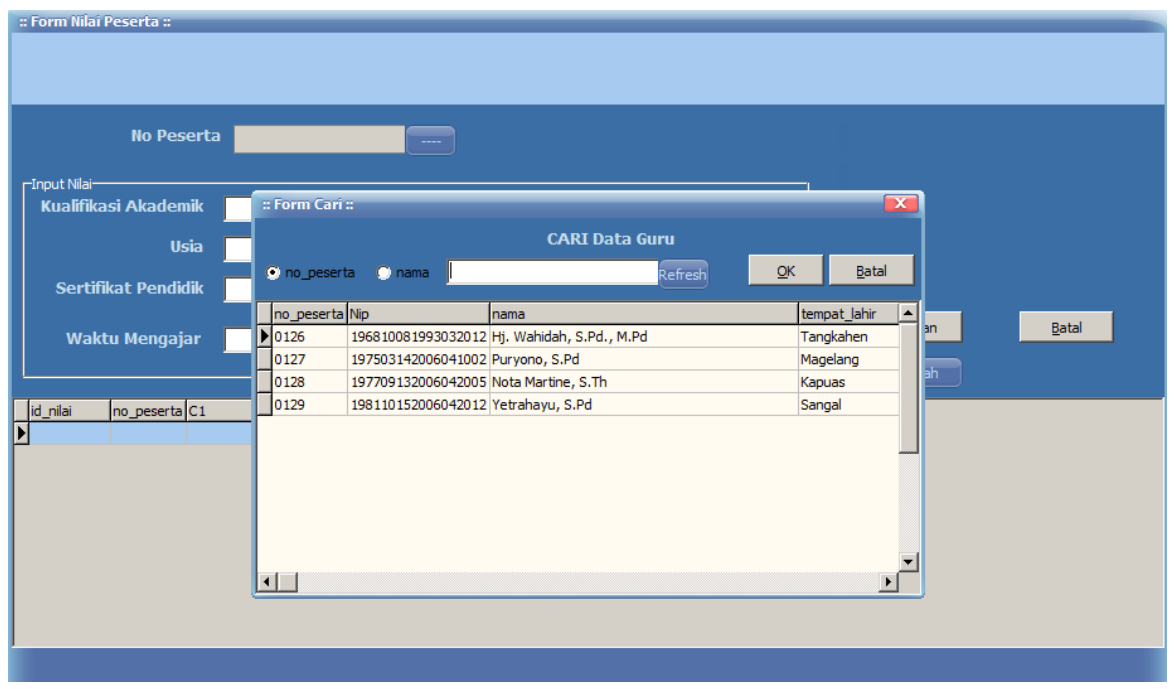

Gambar 5. Pilih Salah Satu Data Guru

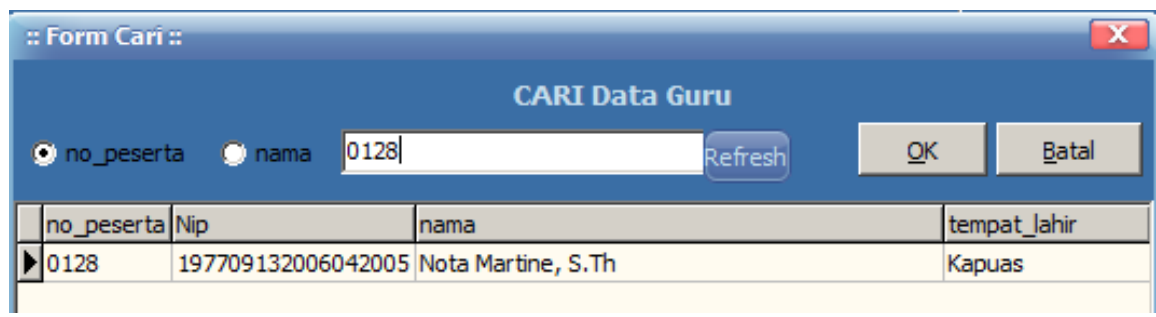

Gambar 6. Pilih Data Guru Berdasarkan Nomor Peserta

2) Pada kolom kriteria Kualifikasi Akademik terdapat pilihan D4/S1, S2 dan S3. Pada kolom Usia terdapat pilihan usia 23-30, 31-40, 41-50 dan >51. Pada kolom Sertifikat Pendidik terdapat pilihan 1 sertifikat atau lebih dari $1(>1)$ sertifikat. Pada kolom Waktu Mengajar terdapat pilihan 24-25 jam, 26-27 jam, 28-29 jam dan >30 jam. Pada kolom Masa Kerja terdapat pilihan $<5$ tahun, 6-10 tahun, 11-15 tahun, 16-20 tahun dan $>21$ tahun. Pada kolom Golongan terdapat pilihan III A, III B, III C, III D, IV A dan IV B. Pada kolom Jabatan terdapat pilihan Guru, Wakil Kepala Sekolah dan Kepala Sekolah. Pilih salah satu dari items yang ada di tiap-tiap kolom kriteria berdasarkan data guru tersebut. 


\section{JURNAL TEKNOLOGI INFORMASI}

Jurnal Keilmutan dan Aplikasi Biciang Teknik Informatika

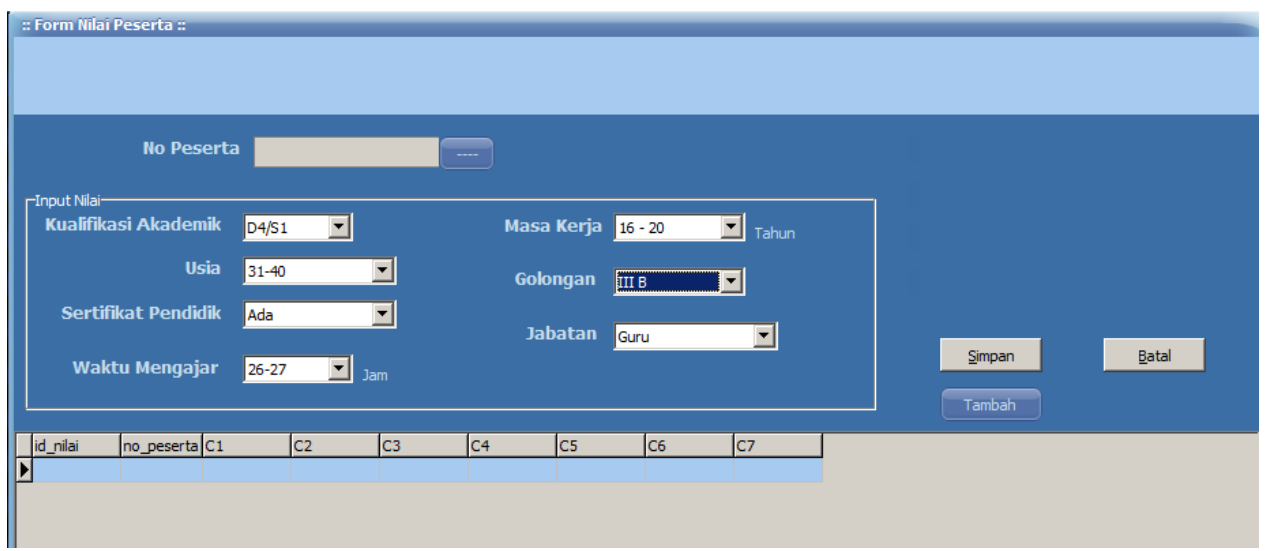

Gambar 7. Inputan Pada Kolom Kriteria Sebagai Bahan Penilaian

3.4 Pengujian Hasil Perangkingan

Pengujian hasil perankingan dilakukan untuk mengetahui seberapa besar keakuratan sistem. Pengujian dilakukan dengan membandingkan hasil perankingan secara manual dengan perankingan yang dilakukan oleh sistem. Berdasarkan data hasil tersebut, dapat dicari perhitungannya masing-masing dengan menggunakan rumus :

$$
V_{i}=\sum_{j=1}^{n} w_{j} r_{i j}
$$

Keterangan

$\mathrm{V}_{\mathrm{i}}=$ Nilai akhir dari alternatif

$\mathrm{w}_{\mathrm{i}}=$ Bobot yang telah ditentukan

$\mathrm{r}_{\mathrm{ij}}=$ Normalisasi Matriks

$\mathrm{x}$ Nilai $\mathrm{V}_{\mathrm{i}}$ lebih besar mengindikasikan bahwa alternatif $\mathrm{A}_{\mathrm{i}}$ lebih terpilih.

i. Tentukan bobot nilai berdasarkan tingkat kepentingan dari tiap-tiap kriteria yang ada.

Tabel 9. Kriteria dan Bobot

\begin{tabular}{cllc}
\hline Kriteria & \multicolumn{1}{c}{ Keterangan } & Bobot (\%) \\
\hline C1 & Kualifikasi Akademik & & 10 \\
\hline C2 & Usia & & 5 \\
\hline C3 & Sertifikat Pendidik Profesional & & 25 \\
\hline C4 & $\begin{array}{l}\text { Waktu yang digunakan untuk tatap muka (mengajar) } \\
\text { seminggu }\end{array}$ & dalam & 25 \\
\hline C5 & Masa Kerja & & 15 \\
\hline C6 & Golongan & & 5 \\
\hline C7 & Jabatan & & 15 \\
\hline
\end{tabular}

ii. Menentukan rating kecocokan setiap alternatif pada setiap kriteria. Sebagai sample dimasukkan 3 data guru. 
Tabel 10. Data Peserta

\begin{tabular}{llccccccc}
\hline \multirow{2}{*}{ No } & \multirow{2}{*}{ Nama Guru } & \multicolumn{7}{c}{ Kriteria } \\
\cline { 3 - 9 } & & C1 & C2 & C3 & C4 & C5 & C6 & C7 \\
\hline 1. & Afifah Yusparina, S.Pd & 0,6 & 0,6 & 0,5 & 0,6 & 0,2 & 0,7 & 0,5 \\
\hline 2. & Grace Natallie, S.Pd & 0,5 & 1 & 0,3 & 0,4 & 0,6 & 0,9 & 0,5 \\
\hline 3. & Putri Neriasi, S.Pak & 0,5 & 0,8 & 1 & 0,6 & 0,4 & 0,9 & 0,5 \\
\hline
\end{tabular}

iii. Membuat matriks keputusan berdasarkan kriteria, kemudian melakukan normalisasi matriks berdasarkan persamaan yang disesuaikan dengan jenis atribut sehingga diperoleh matriks ternormalisasi

$$
\mathbf{X}=\begin{array}{lllllll}
0,6 & 0,6 & 0,5 & 0,6 & 0,2 & 0,7 & 0,5 \\
0,5 & 1 & 0,3 & 0,4 & 0,6 & 0,90,5 \\
0,5 & 0,8 & 1 & 0,6 & 0,40,9 & 0,5
\end{array}
$$

iv. Normalisasi matriks $\mathrm{X}$ menggunakan persamaan 1

Alternatif : Afifah Wulandari, S.Pd

$$
\mathrm{r}_{\mathrm{ij}}=\left\{\begin{array}{l}
\frac{x_{i j}}{\operatorname{Max} x_{i j}} \\
\frac{\operatorname{Max} x_{i j}}{x_{i j}}
\end{array}\right.
$$

$$
\begin{aligned}
& \mathrm{R}_{11}=\frac{0,6}{\max (0,6,0,5,0,5)}=\frac{0,6}{0,6}=1 \\
& \mathrm{R}_{12}=\frac{0,6}{\max (0,6,1,0,8)}=\frac{0,6}{1}=0,6 \\
& \mathrm{R}_{13}=\frac{0,5}{\max (0,5,0,3,1)}=\frac{0,5}{1}=0,5 \\
& \mathrm{R}_{14}=\frac{0,6}{\max (0,6,0,4,0,6)}=\frac{0,6}{0,6}=1 \\
& \mathrm{R}_{15}=\frac{0,2}{\max (0,2,0,6,0,4)}=0,33 \\
& \mathrm{R}_{16}=\frac{0,7}{\max (0,7,0,9,0,9)}=0,77 \\
& \mathrm{R}_{17}=\frac{0,5}{\max (0,5,0,5,0,5)}=1
\end{aligned}
$$

Alternatif : Grace Natallie, S.Pd

$$
\begin{aligned}
& \mathrm{R}_{21}=\frac{0,5}{\max (0,6,0,5,0,5)}=\frac{0,5}{0,6}=0,83 \\
& \mathrm{R}_{22}=\frac{1}{\max (0,6,1,0,8)}=\frac{1}{1}=1 \\
& \mathrm{R}_{23}=\frac{0,3}{\max (0,5,0,3,1)}=0,3 \\
& \mathrm{R}_{24}=\frac{0,4}{\max (0,6,0,4,0,6)}=0,66 \\
& \mathrm{R}_{25}=\frac{0,6}{\max (0,2,0,6,0,4)}=1 \\
& \mathrm{R}_{26}=\frac{0,9}{\max (0,7,0,9,0,9)}=\frac{0,9}{0,9}=1 \\
& \mathrm{R}_{27}=\frac{0,5}{\max (0,5,0,5,0,5)}=\frac{0,5}{0,5}=1
\end{aligned}
$$

Alternatif :Putri Neriasi, S.Pak

$\mathrm{R}_{31}=\frac{0,5}{\max (0,6,0,5,0,5)}=\frac{0,5}{0,6}=0,83$ 


$$
\begin{aligned}
& \mathrm{R}_{32}=\frac{0,8}{\max (0,6,1,0,8)}=\frac{0,8}{1}=0,8 \\
& \mathrm{R}_{33}=\frac{1}{\max (0,5,0,3,1)}=1 \\
& \mathrm{R}_{34}=\frac{0,6}{\max (0,6,0,4,0,6)}=1 \\
& \mathrm{R}_{35}=\frac{0,4}{\max (0,2,0,6,0,4)}=\frac{0,4}{0,6}=0,66 \\
& \mathrm{R}_{36}=\frac{0,9}{\max (0,7,0,9,0,9)}=\frac{0,9}{0,9}=1 \\
& \mathrm{R}_{37}=\frac{0,5}{\max (0,5,0,5,0,5)}=1
\end{aligned}
$$

v. Hasil perhitungan didapatkan matriks ternormalisasi r sebagai berikut:

$$
\begin{aligned}
& \begin{array}{lllllll}
1 & 0,6 & 0,5 & 1 & 0,33 & 0,77 & 1
\end{array} \\
& \begin{array}{lllllll}
0,83 & 1 & 0,3 & 0,66 & 1 & 1 & 1
\end{array} \\
& \begin{array}{llllllll}
r= & 0,83 & 0,8 & 1 & 1 & 0,66 & 1 & 1
\end{array}
\end{aligned}
$$

vi. Proses perankingan diperoleh berdasarkan persamaan 2 berikut:

$$
V_{i}=\sum_{j=1}^{n} w_{j} r_{i j}
$$

Vektor bobot $\mathrm{w}=(0,1,0,1,0,25,0,25,0,1,0,1,0,1)$

$$
\begin{aligned}
& \mathrm{V}_{1}=(0,1)(1)+(0,1)(0,6)+(0,25)(0,5)+(0,25)(1)+(0,1)(0,33)+(0,1)(0,77)+(0,1)(1)=0,1+ \\
& 0,06+0,125+0,25+0,033+0,077+0,1=\mathbf{0 , 7 4 6} \\
& \mathrm{V}_{2}=(0,1)(0,83)+(0,1)(1)+(0,25)(0,3)+(0,25)(0,66)+(0,1)(1)+(0,1)(1)+(0,1)(1)=0,083+ \\
& 0,1+0,075+0,165+0,1+0,1+0,1=\mathbf{0 , 7 2 5} \\
& \mathrm{V}_{3}=(0,1)(0,83)+(0,1)(0,8)+(0,25)(1)+(0,25)(1)+(0,1)(0,66)+(0,1)(1)+(0,1)(1)=0,083+ \\
& 0,08+0,25+0,25+0,066+0,1+0,1=\mathbf{0 , 9 3}
\end{aligned}
$$

vii. Nilai yang terbesar ada pada $\mathrm{V}_{1}$ sehingga alternatif tertinggi adalah Putri Neriasi, S.Pak. Dengan kata lain, Putri Neriasi, S.Pak memiliki kesempatan mendapat sertifikasi paling tinggi diantara 2 (dua) guru lainnya.

\section{Penutup}

4.1 Simpulan

Setelah melakukan penelitian dan pembahasan pada Sistem Pendukung Keputusan Pemilihan Guru-Guru yang Berhak Menerima Sertifikasi, maka dihasilkan kesimpulan sebagai berikut, yaitu:

1. Perancangan Sistem Pendukung Keputusan Pemilihan Guru-Guru yang Berhak Menerima Sertifikasi berbasis desktop ini menggunakan metode pengembangan perangkat lunak Waterfall. Sistem Pendukung Keputusan ini dibangun dengan menggunakan software Delphi 7 dan MySQL sebagai database management system.

2. Dari penelitian menghasilkan sebuah rancang aplikasi baru yaitu sistem pendukung keputusan pemilihan guru yang berhak sertifikasi dengan menerapkan metode Simple Additive Weighting $(S A W)$ sebagai penyedia informasi dalam melakukan proses penghitungan nilai dan memproses perankingan peserta dengan bantuan normalisasi matriks sebagai suatu pencarian terhadap peserta yang lebih berhak menerima sertifikasi sesuai urutan mulai dari nilai teratas sampai nilai paling bawah. Metode ini juga memberikan hasil penilaian beserta perankingan dengan kemungkinan probabilitas yang lebih pantas mendapatkan sertifikasi.

3. Berdasarkan hasil pembahasan analisis dan pengujian Sistem Pendukung Keputusan berbasis dekstop ini,didapatkan hasil keakuratan hampir atau sama dengan hasil penghitungan penilaian manual yang dilakukan oleh Dinas Pendidikan Kabupaten Murung Raya. Dengan demikian, perancangan ini dapat dilanjutkan ke tahap implementasi yang sesungguhnya. 


\subsection{Saran}

Perlu dikembangkan lagi bukan hanya sebagai pengambil keputusan pemilihan guru yang berhak menerima sertifikasi khusus guru PNS saja, melainkan dapat mencakup seluruh guru yang ada di Kabupaten Murung Raya, baik itu guru honorer maupun guru yayasan.

\section{Daftar Pustaka}

[1] Lembaran Negara Republik Indonesia Tahun 2005 Nomor 157, http://luk.staff.ugm.ac.id/atur/UU14-2005GuruDosen.pdf

[2] Mansur, Muslich, 2007. Sertifikasi Guru Menuju Profesionalisme Pendidik, Jakarta : PT. Bumi Aksara

[3] J. W. Satzinger, R. B. Jackson and S. D. Burd, 2011. Systems Analysis and Design in a Changing World, Sixth ed.

[4] McLeod, Raymond Jr dan Schell, George P. 2008. Management Information System: Sistem Informasi Manajemen, Edisi 10/ Jr. Raymond McLeod dan George P. Schell; Diterjemahkan Oleh: Ali Akbar Yulianto Dan Afia R. Fitriati. Jakarta: Salemba Empat.

[5] Romney, Marshall B \& Paul John Steinbart. 2011. Accounting Information System 9th Edn. (Diterjemahkan oleh Dewi Fitriasari dan Deny Arnos Kwary). Sistem Informasi Akuntansi Edisi 9. Jakarta: Salemba Empat.

[6] Turban, Efraim, 2001. Decision Support System and Intelligent System (Sistem Pendukung Keputusan dan Sistem Cerdas). Yogyakarta, Andi

[7] Sprague, R.H. \& Watson H.J. 1993. Decision Support Systems: Putting Theory Into Practice. Englewood Clifts, N.J: Prentice Hall

[8] https://medium.com/skyshidigital/sistem-pengambilan-keputusan-dengan-algoritma-saw-simpleadditive-weighting-524a43ef316 (2 Januari 2020)

[9] http://kelompokspksaw.blogspot.com/2017/12/13-kekurangan-metode-spk-saw.html https://medium.com/skyshidigital/sistem-pengambilan-keputusan-dengan-algoritma-saw-simpleadditive-weighting-524a43ef316 (2 Januari 2020)

[10] Sugiyono, 2013. Metode Penelitian Kuantitatif , Kualitatif , dan R\&G, Bandung, Alfabeta 